\title{
Chapter 2 \\ The different types of research reactors, overall global situation, uses and associated risks
}

\subsection{Types of research reactors}

\section{Different types for different applications}

Because research reactors are designed differently according to their purpose or application, they can be classified accordingly. In practice, we make a distinction between:

- Material Testing Reactors (MTRs), designed mainly for studying and testing different materials and nuclear fuels, especially those used in power reactors, or for producing radioisotopes for medical use;

- reactors with "neutron channels 8 ", often referred to as "neutron beams outside" reactors, which are mainly used for fundamental research, e.g. neutron scattering experiments;

8. In this document, the following expressions will be used: "neutron channel" will refer to the assembly consisting of - in the reactor pool - a "thimble" or "beam tube", (the end of which nearest the core, in the heavy water tank, is known as the "beam tube end") and - outside the reactor pool (in the experiment hall) - a "neutron guide". 
- critical assemblies (or critical mockups), with very low thermal power, used particularly to determine nuclear data for validating software used to simulate core neutronics (of power or research reactors);

- reactors for safety studies, which are used specifically for studying accident situations representative of those likely to occur in power reactors, such as loss of fuel cooling and reactivity injection ${ }^{9}$, which could lead to melting of fuel and the release of fission products into the environment;

- training reactors, which are generally of low thermal power and are used to train nuclear industry personnel and for teaching at universities.

\section{Different designs}

Unlike power reactors, which have gradually become limited to a small number of designs, in the case of research reactors there is a wide range of different designs. Among the wide variety of research reactors, there are two main groups:

- heavy-water reactors ${ }^{10}$ (in which heavy water is used as coolant, moderator or neutron reflector),

- reactors cooled and moderated by light water.

The other types of research reactors include those in which the neutrons are moderated by graphite, aqueous homogeneous reactors, which use a uranium nitrate or sulphate solution, and fast neutron reactors, which do not need a moderator but can use a mixed uranium oxide and plutonium oxide fuel.

- Heavy water reactors:

Heavy water reactors are "tank in pool" reactors. They can produce intense fluxes of thermal neutrons, which are extracted from the core by means of neutron channels, generally for fundamental physics research. The moderating properties of the heavy water enable neutron beams to be produced that contain no fast

9. In order to characterise the risk of core runaway, the concept of reactivity is used: it is a magnitude (represented by $\rho$ ) for measuring how far a core is from its just-critical state $(\rho=0)$. Typically, the inadvertent removal or ejection of a control or safety rod from the reactor core, because it reduces the proportion of neutron-absorbing materials in the core, will lead to excessive core "reactivity" and therefore an increase in heat, at least locally. If this is not controlled by the reactor's surveillance and protection systems, it can cause significant damage or even cause fuel elements in the core to melt. The terms "insertion" and "injection" are interchangeable in this context. The term "power excursion" refers to the power transient caused by a reactivity injection.

10. For reactors using uranium-235 fuel, it is the slow, low-energy neutrons $(E=0.025 \mathrm{eV})$ that have the highest probability of causing fission. With an effective moderator, the neutrons resulting from the fission of uranium-235 are slowed down until their kinetic energy is around the thermal agitation energy of the scattering medium $(0.025 \mathrm{eV}$ at a temperature of $300 \mathrm{~K})$, without being absorbed. Most fissions occur at this energy, and the reactor is referred to as a thermal-neutron reactor. Moderators are therefore used; heavy water $\left(D_{2} O\right)$ is the best moderator, ahead of graphite, beryllium and light water $\left(\mathrm{H}_{2} \mathrm{O}\right)$, in descending order. 
neutrons (considered to be parasites), which are ideal for experiments on the physics of matter. However, these reactors are not really suitable for material testing because the presence of a closed tank to hold the heavy water makes it difficult to access equipment near the reactor core.

- Light water reactors:

Light water reactors, also known as pool-type reactors, can have an open core or a core in an enclosed tank, in both cases in a pool ("tank in pool" reactor type). These reactors are multi-purpose facilities generally used for the irradiation of different materials. Of the different types of research reactor currently in operation throughout the world, these are the most common. Figure 2.1 below shows the HFR reactor ${ }^{11}$, a closed-tank reactor, at Petten in the Netherlands.
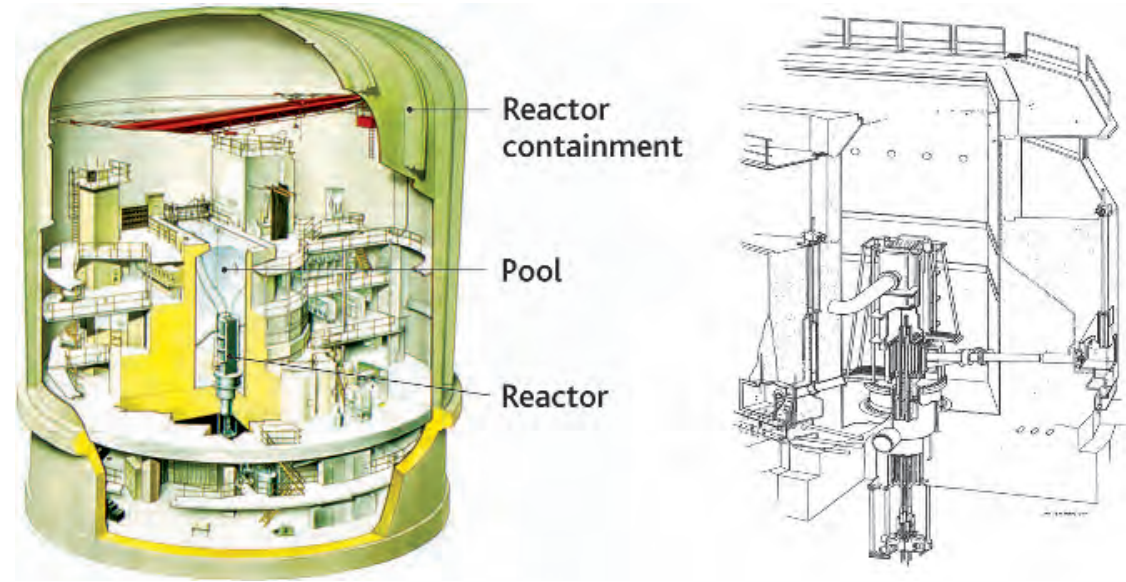

Figure 2.1. The HFR reactor at Petten, a closed-tank pool-type reactor. (C) NRG.

Open core pool-type reactors generally give easy access to the irradiation locations, but their low pressure of use (similar to hydrostatic pressure) means that there is less removable heat and therefore that the neutron fluxes are more limited.

In pool-type reactors with a closed tank, higher thermal power levels can be achieved (with greater pressures than in open core reactors), but they are more difficult to use for experimental irradiation because of the need for devices that penetrate the tank for closer access to the core; the neutron fluxes outside the tank are lower because of neutron absorption by the tank material.

Open core pool-type light water reactors operate at low pressures (a few bars), determined by the hydrostatic pressure of the height of water above the core (around ten metres) plus the discharge pressure of the pumps circulating the water in the core. With light water reactors where the core is in a closed tank and heavy water reactors, the operating pressures can be significantly higher (around 10 to 20 bars).

11. High Flux Reactor. 
Of the closed-vessel reactors, it is worth mentioning the design used for the BR2 ${ }^{12}$ reactor, developed by SCK CEN at the $\mathrm{Mol}$ research centre in Belgium ${ }^{13}$, to make it easier to conduct experiments. This reactor, rated at $100 \mathrm{MW}$, is moderated and cooled by light water at a pressure of 22 bars; the core consists of a beryllium matrix. To facilitate access to the irradiation locations, the core tank is in the shape of a hyperboloid of revolution (diabolo - figure 2.2) with the core in the narrow part. Its top cover, with a diameter around twice that of the narrow part, allows more room for the penetration sleeves of the irradiation devices, which are inclined slightly off the vertical ${ }^{14}$.

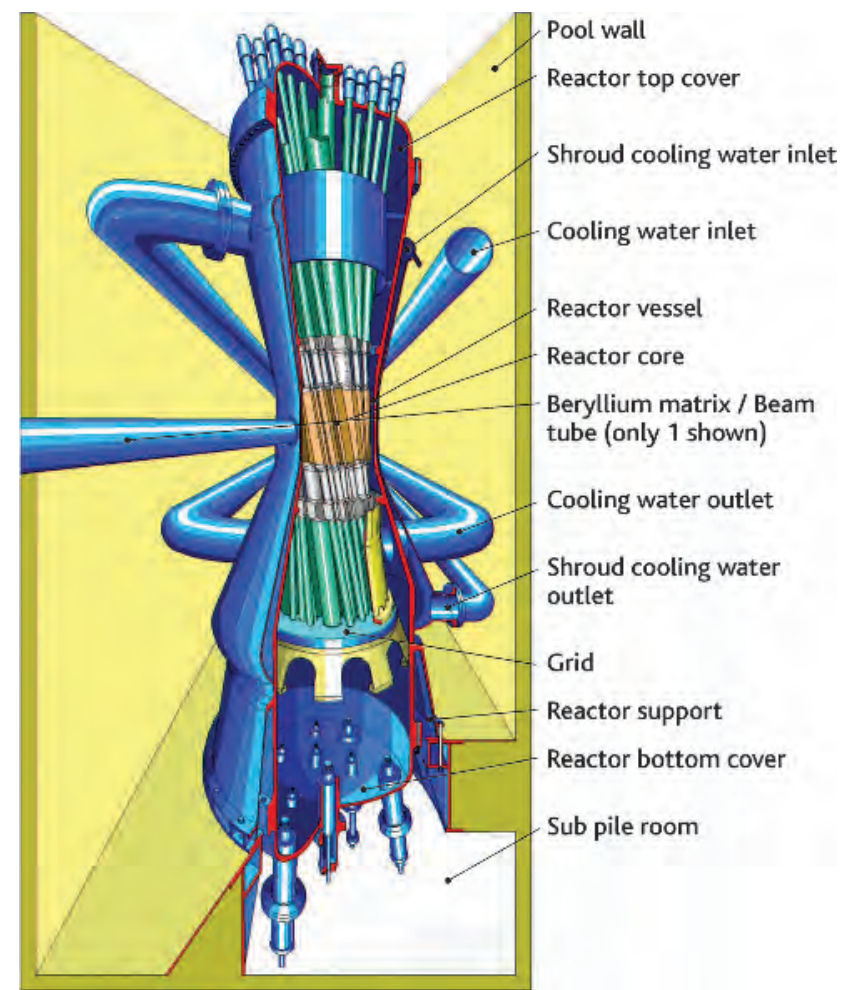

Figure 2.2. Diagram of the BR2 reactor. (C) SCK CEN.

\section{Fuel and core of research reactors}

In general, the cores of research reactors consist of fuel elements, control and safety elements containing materials that absorb neutrons, reflector elements to reduce

12. Belgian Reactor 2.

13. One of the biggest producers of radioisotopes for medical use.

14. "Les réacteurs de recherche", Francis Merchie, Encyclopédie de l'énergie, 2015. 
leakage of the neutrons produced in the reactor core, and spaces in which materials for irradiation can be placed.

The description below tends to refer to pool-type reactors.

With these reactors, the constituents of the core are placed on a grid supported by a metal structure at the bottom of the pool filled with demineralized water.

Fuel elements ${ }^{15}$ can come in the form of an assembly of uranium oxide-based rods, but more often they are in the form of plates of a uranium alloy-based fuel ( $\mathrm{UAl}_{\mathrm{x}}{ }^{16}$ or $\mathrm{U}_{3} \mathrm{Si}_{2}$ ) clad in an aluminium alloy (by "co-rolling") (figure 2.3), placed (the plates are crimped) in a vertical shell (figure 2.4) channelling the cooling water, which also acts as the moderator. The core reflector is generally made from beryllium or graphite. It can also be a tank of heavy water surrounding the reactor core. In the case of "neutron beams outside" reactors, there are openings in the side walls of the pool for the neutron channels to go through.

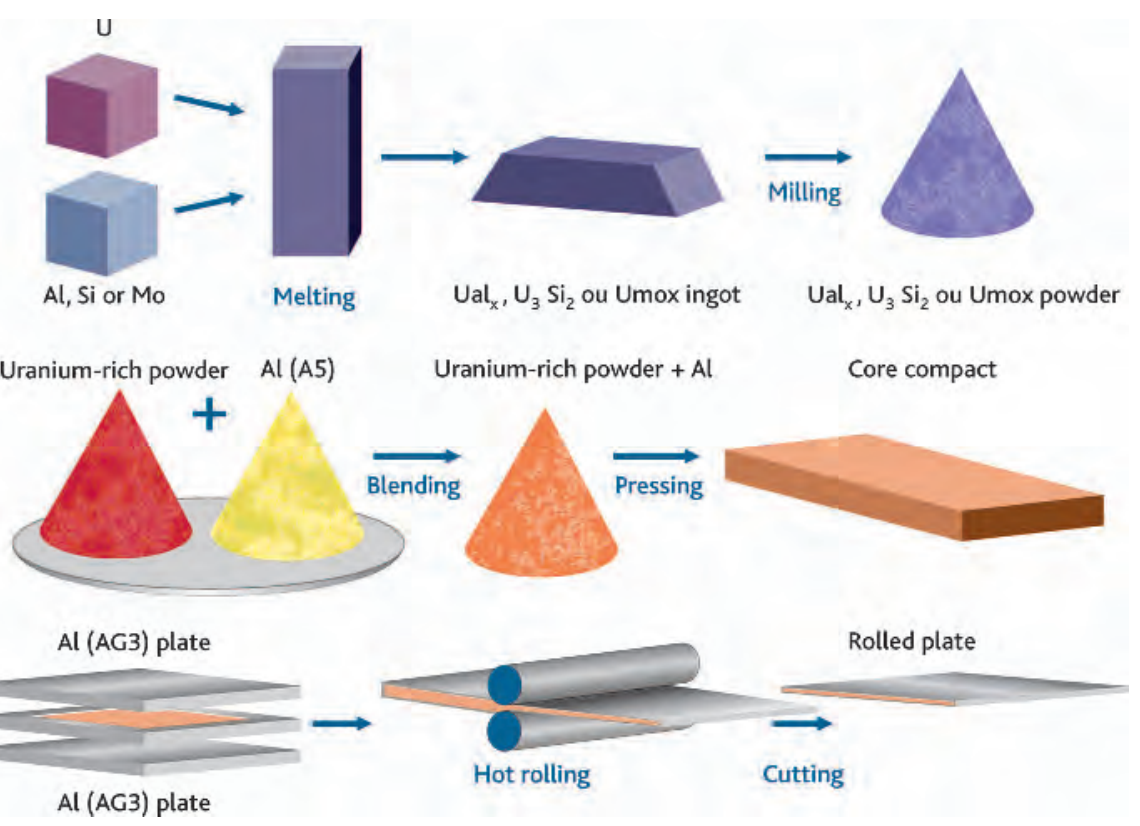

Figure 2.3. Stages in the "co-rolling" fuel plate fabrication process. The fuel core is a blend of fuel powder $\left(\mathrm{UAl}_{\mathrm{x}}, \mathrm{U}_{3} \mathrm{Si}_{2}, \mathrm{UMo}_{\mathrm{x}}\right)$ and aluminium from melting $\mathrm{U}$ and $\mathrm{Al}, \mathrm{Si}$ or Mo. (c) Georges Goué/IRSN.

Although some of the first research reactors could operate with natural uranium (containing $0.7 \%$ of its fissile isotope uranium-235), benefiting from the excellent

15. For more details, see the CEA's publication entitled "Nuclear fuels", a Nuclear Energy Division Monograph, 2008, especially the "Research reactor fuels" chapter.

16. This is usually referred to as UAl. The same applies for $\mathrm{UMo}_{\mathrm{x}}$, which will be discussed later on and is commonly referred to as UMo. 


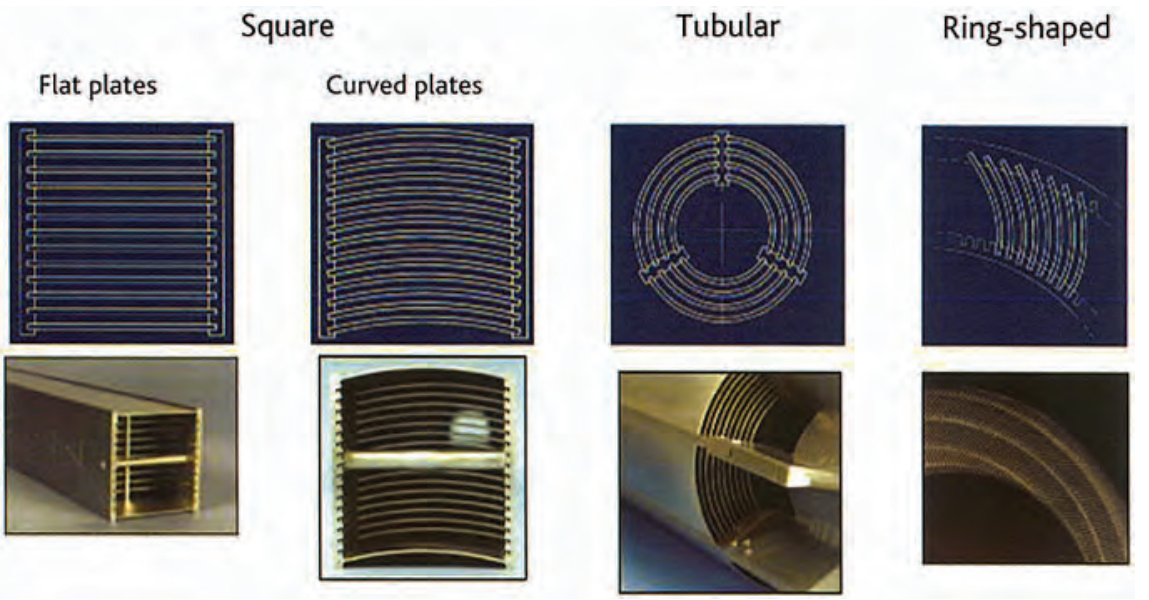

Figure 2.4. Different types of research reactor fuel elements and fuel assemblies. () AREVA-CERCA.

neutronic properties of heavy water or graphite as moderator and reflector ${ }^{17}$, most use uranium enriched to between $20 \%$ and $93 \%$ uranium-235.

Among the pool-type reactors widely used throughout the world, it is worth mentioning the TRIGA (Training, Isotope, General Atomics) reactors designed and built by the American company General Atomics ${ }^{18}$ (see figure 2.5 showing two of these reactors): some of their characteristics, particularly related to the fuel and the core, are of particular interest.

Nearly forty TRIGA reactors are currently in service. The most powerful of these reactors is the TRIGA reactor at the Pitesti nuclear centre in Romania, which has a thermal power rating of $14 \mathrm{MW}$. The thermal power of the other TRIGA reactors ranges from a hundred $\mathrm{kW}$ to $3 \mathrm{MW}$.

The core of a TRIGA reactor is positioned at the bottom of a pool containing demineralized water. It has a graphite or beryllium reflector and generally consists of around a hundred fuel rods containing pellets made from a blend of uranium and zirconium hydride $(\mathrm{UZrH})$ clad with stainless steel or 800 alloy ${ }^{19}$. The uniform blend of uranium (enriched to $19.75 \%$ of uranium-235) and zirconium hydride (used as moderator) produces significant and immediate neutron feedback if the temperature of the blend increases

17. The NRX (National Research eXperimental) and NRU (National Research Universal) reactors in Canada, for example.

18. In 1996, General Atomics joined forces with the French company CERCA (Compagnie pour l'étude et la réalisation de combustibles atomiques, a subsidiary of AREVA (Orano)) to create TRIGA International. Since then CERCA has been responsible for the fabrication of the fuel assemblies for TRIGA reactors.

19. Iron, nickel and chrome alloys, which combine good ultimate tensile strength with excellent resistance to oxidation and carburization at high temperatures in many aqueous environments. 

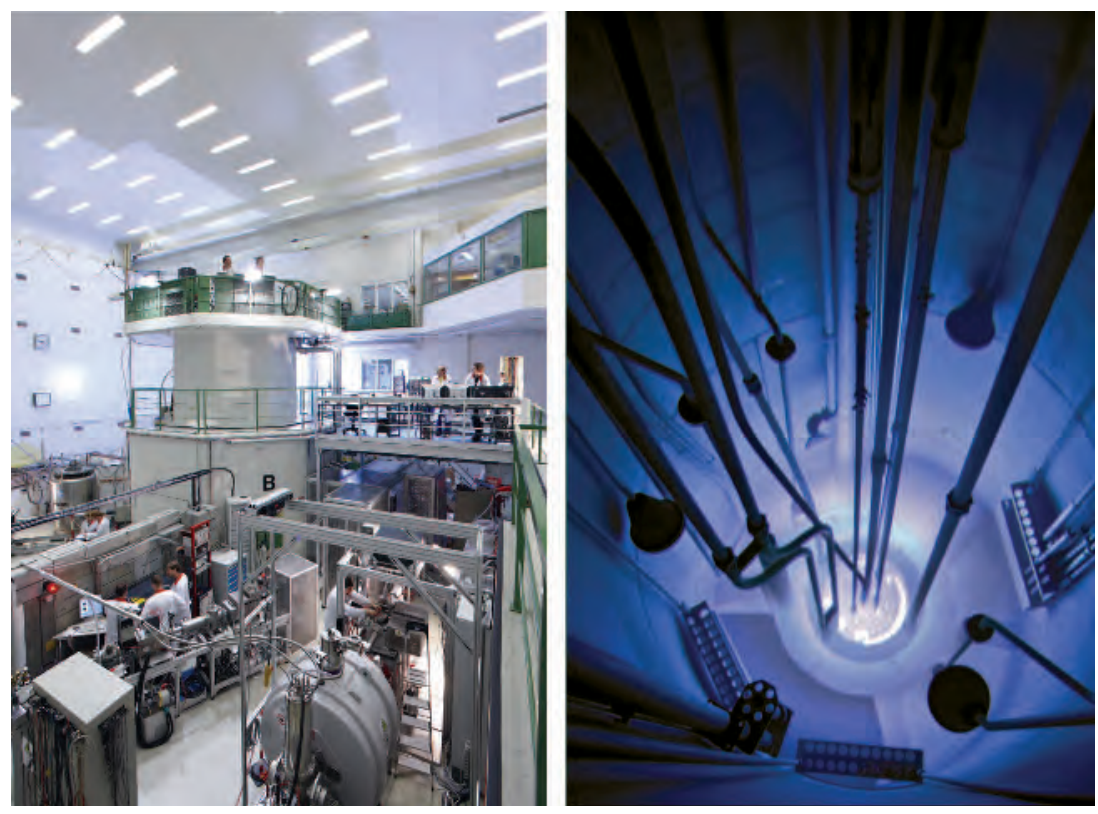

Figure 2.5. Left, the TRIGA reactor in Mainz, Germany. (C) Thomas Hartmann, Johannes Gutenberg University Mainz; right, the TRIGA reactor at the University of Oregon, USA. (c) Oregon State Radiation Center and School of Nuclear Science and Engineering.

(reactivity coefficient of around $\left.-10 \mathrm{pcm}^{20} /{ }^{\circ} \mathrm{C}\right)^{21}$. Because of the good metallurgical stability of this fuel and its ability to function at high temperatures (normally $750^{\circ} \mathrm{C}$, though the fuel blend is stable at up to $1,150^{\circ} \mathrm{C}$ ), and the high negative reactivity coefficient, the TRIGA reactor can be "pulsed" by injecting reactivity at very high power levels (of up to $22,000 \mathrm{MW}$ in the case of the TRIGA reactors currently in operation) for fractions of a second. The rapid increase in power is quickly brought to a halt by the negative reactivity effect of the moderator. It is also worth noting that $\mathrm{UZrH}$ fuel has good fission product retention potential compared to fuel plates made using aluminium.

\subsection{Global situation}

\subsubsection{Statistical data}

According to the RRDB database 22 - data from May 2018 - held by the International Atomic Energy Agency (IAEA), 807 research reactors have been built throughout the

20. pcm: per cent mille.

21. The coefficient $\Delta \mathrm{k} / \mathrm{k} /{ }^{\circ} \mathrm{C}$, representing the relative variation in the neutron multiplication factor by increasing the temperature by one degree Celsius.

22. Research Reactors Data Base. The figures in this database include research reactors cover not just civil nuclear facilities. 
world and 23 are planned or are under construction. Among the reactors already built, 430 have been decommissioned (more than half of these are in the USA), 223 are operational, and the other 154 are in extended shutdown without utilization (or not yet decommissioned). Around:

- $27 \%$ of research reactors have a thermal power of less than $1 \mathrm{~kW}$;

- $35 \%$ have a thermal power of between $1 \mathrm{~kW}$ and $1 \mathrm{MW}$;

- $38 \%$ have a thermal power of more than $1 \mathrm{MW}$.

Among the reactors in operation worldwide:

- more than $50 \%$ are MTRs and multi-purpose reactors (also produce, radioisotopes, have "neutron beams outside", etc.);

- around $20 \%$ of them are very low power critical assemblies;

- just over $10 \%$ of them are small reactors mainly used for education and training.

The Russian Federation has the largest number of research reactors (in operation or temporarily shut down) (54), followed by the USA (50), China (16), Japan (9), Germany (7) and France (5) ${ }^{23}$. Many developing countries also have research reactors or are planning to acquire them. Nine research reactors are under construction throughout the world and fourteen are planned.

Despite the growing interest in research reactors in developing countries, the total number of these reactors globally is steadily diminishing (the reduction in numbers since 2005 means that, on average, one research reactor is being closed per year). This may be due to the ageing of some facilities, which can only be brought up to a safety level considered acceptable today by carrying out major upgrading or modification work. It could also be due to a lack of funds to operate and maintain them, or even to there being no utilization programme for them. In this regard, it should be noted that nearly $40 \%$ of research reactors are underused (154 are in extended or permanent shutdown).

\subsubsection{General nuclear safety and non-proliferation issues}

Despite the variety of designs and uses, some important general safety issues have been raised in relation to many of the research reactors in operation throughout the world; these issues mainly concern:

- maintaining safety levels as facilities age (in the broadest sense, including as equipment becomes obsolescent),

- safety management by their operators,

- the effectiveness of regulatory monitoring of their safety.

23. The ISIS, RHF, CABRI, ORPHÉE and MASURCA reactors are counted here in the RRDB database. 
These issues have been highlighted particularly by the various safety reports produced by the IAEA within the framework of different meetings and technical workshops, based on experience feedback from its activities concerning research reactor safety, including the results of numerous "safety assessment ${ }^{24 "}$ missions.

Another key generic issue is the "conversion" of research reactors originally designed to use fuel highly enriched with uranium-235 to use less highly enriched fuel (containing no more than $20 \%$ uranium-235), for non-proliferation reasons.

Management of ageing and the "conversion" of research reactors that use highly enriched fuel are discussed in more detail below.

Moreover, it was stated above that nearly $20 \%$ of research reactors are in extended shutdown, which means that they are not used but there are no clear plans for their future. This is a cause for concern for the IAEA, which is engaged in various actions aimed in particular at improving the utilization of research reactors.

\subsubsection{Management of research reactor ageing}

There are two aspects to this issue:

- actual ageing, which is the result of various damage mechanisms - or pathologies - that can affect components (metal structures, civil engineering works, cables and other electrical equipment, etc.) over time, which can lead to latent deterioration (cracking, brittleness, etc.) despite the design, construction and operational precautions ${ }^{25}$ taken;

- equipment obsolescence in respect of the most recent technologies, standards and safety requirements.

The IAEA's experience feedback reports show that ageing and obsolescence are among the leading causes of incidents at research reactors throughout the world.

Ageing and obsolescence especially affect material testing reactors, some of which are also used to produce radioisotopes for medical use.

A country's decision to renovate a research reactor or to shut it down, replacing it (or not) with a new reactor, will depend on a number of factors, in particular:

- how much the facility is used;

- the radioisotope needs of the country (or region) for medical applications;

- the experimental studies required to support an existing or planned national nuclear power generation programme;

- changes in the reactor's environment (urban, industrial, etc.);

24. The Integrated Safety Assessments of Research Reactors (INSARR).

25. Particularly in the form of margins, corresponding to "provisions" in the case of damage mechanisms that can be anticipated and quantified. 
- the scale and the feasibility of the renovation work required, as well as the cost, including to reach a satisfactory safety level.

It should be noted that it is generally possible to replace all the components of research reactors, except their civil engineering works. This has been confirmed by the major renovations carried out on a number of different research reactors.

As with other types of nuclear facilities, ageing and obsolescence in the case of research reactors can lead to a reduction in safety margins (as regards dreaded phenomena) if those changes are not detected or corrected in time.

Obsolescence can in particular lead to difficulties procuring spare parts to replace safety-related components.

Ageing can affect safety-related equipment, e.g. corrosion of fuel element cladding, the reactor pool liner or coolant system pipes. It can also increase the risk of "common failure mode" ${ }^{26}$ of redundant components.

Although for many research reactors, most structures, systems and components $\left(\mathrm{SSC}^{27}\right)$ are replaceable, in order to manage ageing a systematic approach is necessary, combined with an effective programme for this management. This means, for example, the use of materials with good corrosion resistance or materials that are compatible with one another (for welding, for radiation protection in pools ${ }^{28}$, etc.) or setting up equipment inspection and maintenance programmes, including the surveillance of representative samples specifically to monitor and anticipate the ageing of safety-related equipment. Generally, all parameters that could affect the ageing of facilities and lead to the degradation of safety-related structures, systems and components should be monitored appropriately during the life of a reactor.

Ageing management should be set up and carried out in a proactive and anticipative way, during the different phases in the life of a research reactor. For example, modifications made to a research reactor or its experimental devices should not obstruct inspections or tests designed to detect signs that safety-related structures, systems and components are ageing - and if possible should facilitate them. This can be achieved by making the equipment accessible (at the initial design stage of the facility) and keeping it so (during operation), though without exposing those carrying out the inspections, or anyone else, to ionizing radiation.

Finally, existing experience feedback on ageing, including from industrial facilities, whether specific to the reactor in question or generic, must be taken into account as part of ageing management. The IAEA keeps a database on this subject, the aim of which is to share this knowledge worldwide.

26. Failures of several components due to the same cause.

27. "Structures, systems and components" is a standard expression used particularly in IAEA standards.

28. For example, lead can cause aluminium structures to corrode, depending on the physical and chemical state of the water. 


\subsubsection{2. "Conversion" of research reactors using fuel highly enriched with uranium-235}

Where research reactors using fuels highly enriched with uranium-235 are used, there is a risk that this fissile material could be diverted to a non-peaceful use. This risk is particularly high given that the low radioactivity level of the fuel makes it easy to handle.

Highly enriched uranium differs from the natural uranium or low enriched uranium used in power reactors because of its high uranium-235 content (which can be as much as $93 \%$ ). The maximum "non-proliferation" content is considered to be $20 \%$, given the risks associated with the diversion or theft of non-irradiated fuels and the risks related to the production of plutonium during the irradiation of low enriched fuels in a reactor.

In the 1950s and 1960s, the USA and the Soviet Union started to export highly enriched uranium as part of their civil nuclear cooperation programmes (especially the US Atoms for Peace programme launched in 1954).

In 1978, the US Department of Energy (DOE) launched the Reduced Enrichment for Research and Test Reactors (RERTR) programme, the aim of which was to "convert" research reactors using fuel highly enriched with uranium-235, of US origin, to the use of low enriched fuel (less than 20\%). In the mid-1980s, the programme was extended to include facilities that produce radioisotopes, in particular with the development of technologies to produce molybdenum-99 for nuclear medicine using low enriched with uranium-235 targets.

In the early 1990s, the programme was extended again, in collaboration with Russian institutes, this time to reactors using highly enriched fuel of Russian origin. This concerned highly enriched fresh and spent fuel at research reactors in Poland, Serbia, Ukraine and Uzbekistan, as part of their "conversion" to low enriched fuel.

After the terrorist attacks of 11 September 2001 on the World Trade Center in New York, efforts and resources to reduce the enrichment with uranium-235 of fuels used in research reactors were stepped up, especially with the launch by the US administration of the Global Threat Reduction Initiative programme in 2004, which brought the RERTR programme and other US initiatives together under a single umbrella. In particular it aimed to tighten the licensing conditions for exports of highly enriched uranium for research reactors and to take back any exported highly enriched nuclear fuels after use, to keep them secure.

From the launch of the RERTR programme to the end of 2011, some 75 research reactors had been converted to low enriched fuel or had been permanently shut down (out of the 129 research reactors selected for conversion under this programme, including American university reactors). The programme objective is to complete the "conversion" of the remaining reactors by 2020, bearing in mind that, for 28 of them, "conversion" requires the "qualification" of a new high density UMo ${ }^{29}$ fuel (containing around 7 grammes of uranium per $\mathrm{cm}^{3}$ ). 
It is worth noting that the majority of "conversions" in developing countries have been carried out in cooperation with the IAEA and that "conversion" has offered some of them an opportunity to renovate safety-related equipment.

\subsection{Uses of research reactors and main related risks}

A number of research reactors on university or research organization sites are used to train students, engineers and nuclear industry personnel, including personnel who operate research reactors and power reactors, and also nuclear safety authorities.

Research reactors are also used for fundamental and applied research, especially in the fields of nuclear physics and matter sciences, and for activation analysis, radiochemistry and nuclear medicine. They can be used to produce a wide variety of radioisotopes for medical or industrial applications, and for agriculture and research, and to create materials modified by transmutation ${ }^{30}$ for the electronics industry. They can also be used to test different types of nuclear fuel and to study the behaviour of different materials under irradiation or in simulated accident conditions.

These different research reactor uses are discussed in more depth in the next sections. It is also worth reading the report produced by the IAEA in 2007 giving a detailed overview of the different uses of research reactors throughout the world ${ }^{31}$.

\subsubsection{Training}

In principle, all research reactors can be used for education and vocational training in the nuclear field. But for safety and accessibility reasons, low power research reactors (up to a few hundred kilowatts) are best suited to training activities, which can include making neutron measurements and radiological protection measurements, and characterizing reactor cores by establishing the neutron-absorbing rod worth curve and measuring the temperature coefficient and power distribution. This type of reactor also enables trainees to acquire knowledge and practical experience of operating a nuclear reactor (approach to criticality, divergence, etc.). It is obviously important to use specific core configurations with low potential reactivity to prevent reactivity accidents if trainees do something wrong. It should also be noted that setting safety limits, a common operation in reactors used for teaching, requires special care from the point of view of human and organizational factors, especially on the part of trainers and operating personnel.

\subsubsection{Fundamental research}

The neutron beams of research reactors can be used for research into nuclear physics or the physics of condensed matter and to study crystalline structures by thermal

30. Doping of silicon for the manufacture of electronic components.

31. Technical Reports Series No. 455: "Utilization related design features of research reactors: a compendium", 2007. See also the CEA publication "Research Nuclear Reactors", a Nuclear Energy Division Monograph, 2012. 
neutron diffraction. Neutrons, which have a similar unit mass to that of a hydrogen atom and have a neutral electrical charge, can easily penetrate most materials and are therefore ideal for exploring matter. Thermal neutrons travel at around 2,200 m/s, and their wavelength is $0.18 \mathrm{~nm}$ (nanometres), which is perfect for studying crystalline structures through diffraction because it is the same order of magnitude as the lattice size of crystals ${ }^{32}$.

The reactors best suited to neutron scattering and diffraction experiments and studies of the physics of solids are generally the reactors with a thermal power greater than ten megawatts and a neutron flux of more than $10^{14}$ neutrons. $\mathrm{cm}^{-2} \cdot \mathrm{s}^{-1}$.

Using a "cold source" containing liquid hydrogen or liquid deuterium (at a temperature of around 20K) or a "hot source" containing graphite (at a temperature of around $1,500 \mathrm{~K}$ ) makes it possible to move the neutron energy spectrum and obtain higher or lower wavelengths for certain types of research. Using neutron channels, which can be up to a hundred metres long, is a way of increasing the number of experiments installed around the reactor.

The main risks associated with experiments conducted using neutron channels are normal industrial risks and irradiation risks for the experimenters. Severe irradiation of experimenters has happened at various facilities, due either to malfunctioning safety devices (such as neutron beam shutters, radiation monitors or radiation measurement and signalling devices), or to failure to respect safety instructions. Many of the experimenters affected have been from external organizations and have not necessarily been familiar with the different risks associated with the experimentation zones where they were working. As a result of these irradiation incidents, operators have taken measures to make experimenters more aware of the risks associated with the areas they are working in (e.g. putting up notices at the entrance to each experimentation zone showing the conventional and radiological risks in that zone). Material changes have also been made, e.g. an audible and visual alarm being triggered whenever there is unauthorised access to an experimentation zone where the dose rate is above a pre-set value.

Lastly, the risks associated with "cold sources" and "hot sources", especially the risks of hydrogen or deuterium explosion and of steam explosion (through the interaction of graphite and water), which are likely to affect the core of a reactor or its confinement "barriers", should be addressed in the context of the safety demonstration ${ }^{33}$ for that reactor.

\subsubsection{Experimental irradiation}

Research reactors with a thermal power above ten megawatts are the facility of choice for studying and qualifying nuclear fuels and the structural materials and components used in power reactors (vessels, internal equipment, neutron absorbers, etc.).

32. "Les réacteurs de recherche", Francis Merchie, Encyclopédie de l'énergie, 2015.

33. The measures taken by the operator to obtain an appropriate level of safety at the facility should be described in the documents justifying the rationale behind those measures and their adequacy, usually known as the "safety demonstration". 


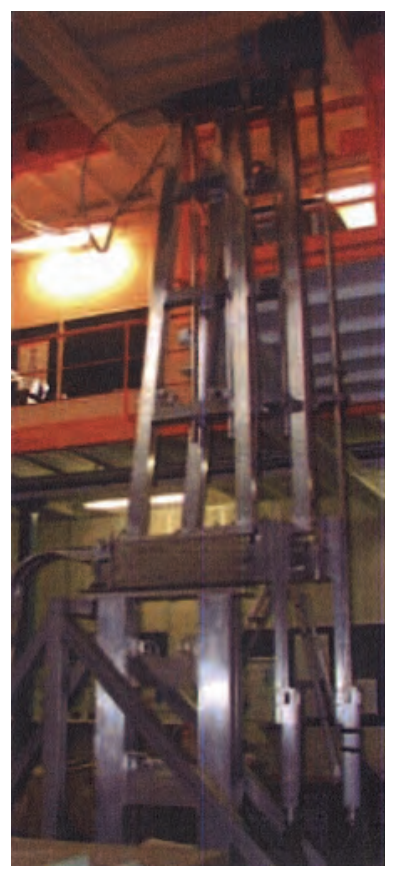

Figure 2.6. Telescopic device at the OSIRIS reactor used to carry out slow power ramps, according to IAEA Report 455. C DR.

Irradiation can be carried out under conditions representative of the neutronics and thermohydraulics of a power reactor in normal operation or, in the case of some reactors, under conditions representative of accident situations at power reactors, such as reactivity insertions or reductions in coolant flow rate to the reactor core, though not severe conditions (e.g. core melt), which are studied specifically using safety testing reactors.

The use of research reactors for this type of irradiation has major advantages over the use of power reactors:

- the higher neutron flux means that the intended irradiation doses can be obtained more quickly (e.g. for studying the ageing of materials subject to irradiation);

- having the ability to instrument the samples better means that more precise measurements can be made of temperature, pressure and neutron flux;

- being able to move the studied fuel samples closer to the reactor core using a (telescopic) "displacement device" makes it possible to simulate slow power ramps $^{34}$ (figure 2.6);

34. Slow changes in power in respect of rapid transients ("pulses"). 
- the risks are lower if an accident occurs while an irradiation experiment is taking place.

The irradiation is generally carried out in experimental devices containing the fuel samples or materials to be irradiated under clearly defined conditions in terms of temperature, pressure, neutron flux and surrounding fluid (inert gas, water as liquid or steam, liquid sodium, etc.).

Every irradiation device must be specially examined from a safety point of view, looking particularly at the risks from possible interactions between the device and the reactor, i.e. the potential impact of the device on the safety of the reactor and other "experiments", and the impact, on the safety of the device, of events (connected with the reactor itself or events such as internal or external hazards) taken into account in the design of the reactor and the associated safety demonstration.

The experimental devices used include irradiation capsules - which are not instrumented - and irradiation loops, containing water, gas or molten metal (e.g. sodium for sodium-cooled fast neutron reactors).

Irradiation capsules generally have two external physical "barriers" (metal envelopes) between the radioactive material and the outside, the integrity of which is surveyed by monitoring the pressure of the thin gas layer (nitrogen or helium) between the two barriers. The safety of the capsules relies on design choices justified by calculations of the heating and increase in pressure of their different components during irradiation, and on the chemical compatibility ${ }^{35}$ of the materials used. Incidents have occurred involving irradiation capsules, where the barriers have burst or their integrity has been lost, leading to contamination of the pool or other reactor structures, or even to the irradiation of experimenters.

Irradiation loops can be used to study the behaviour of nuclear fuels used in the different types of nuclear reactors, under conditions representative of normal, incident or accident operating conditions in power reactors. These loops which, like the irradiation capsules, have envelopes to act as barriers, differ in that they have a circuit to cool the samples being studied. As explained above, the coolant can be water (pressurized), a gas or even a molten metal.

The different parameters of an experimental irradiation device (pressures, temperatures, coolant flow rates in the case of loops, etc.) are continuously monitored while the irradiation is carried out. Security systems trigger automatic reactor scram or the device itself to be brought back to a safe state (e.g. if a pressurized loop loses pressure), as soon as predefined limits are exceeded.

The main risks associated with irradiation loops include:

- the risk of contamination and irradiation of personnel if the integrity of the loop barriers is lost;

- the risk of structural damage to the loop and the emission of projectiles, which can affect reactor safety if the fuel sample being tested melts, potentially

35. Risks of eutectic formation, galvanic corrosion (steel in contact with aluminium), etc. 
followed by a steam explosion (melting of the sample can be one of the objectives in some experiments).

Provisions are made to prevent these risks and limit their consequences.

\#FOCUs

\section{Some reactors used specifically for safety tests}

- CABRI (Cadarache Research Centre, France)

Testing of the behaviour of nuclear fuels in cases of rapid reactivity insertions (pressurized water reactors [PWRs], sodium-cooled fast neutron reactors [SFRs]).

- SCARABEE (Cadarache Research Centre, France) - this reactor has been shut down and dismantled

Tests to support the study of melting fuel accidents caused by fuel assembly blockage in SFRs.

- PHEBUS (Cadarache Research Centre, France)

Tests related to cooling accidents in PWRs and the associated fission product transfers.

- NSRR (Nuclear Safety Research Reactor, Tokai Mura, Japan)

Tests to support the study of rapid reactivity insertions in the case of fuels for SFRs and light water reactors.

- TREAT (Transient Reactor Test Facility - Idaho National Laboratories, Idaho Falls, USA)

Tests to support the study of rapid reactivity insertions in the case of various fuels (SFRs and light water reactors, etc.).

\subsubsection{Medical applications}

\subsubsection{Production of radioisotopes}

Research reactors enable radioisotopes to be produced for use in many fields, including nuclear medicine, industry, agriculture and research.

The use of radioisotopes for medical purposes is rapidly increasing globally. Every year more than 30 million examinations and cancer treatments are carried out worldwide. Molybdenum-99 ( $\left.{ }^{99} \mathrm{Mo}\right)$ is one example of a very commonly used radioisotope. It is used to prepare technetium-99m generators; technetium-99m is produced by the $\beta$ decay of molybdenum-99 (half-life 2.75 days). Molybdenum-99 is a fission product obtained by irradiating small UAl fuel plates (the uranium can be enriched to varying degrees). In some research reactors, molybdenum-99 is produced by neutron capture in targets enriched with molybdenum-98. 
The reactors that produce most of the world's molybdenum-99 are old reactors (BR2 in Belgium, HFR (Petten) in the Netherlands, NRU in Canada, SAFARI ${ }^{36}$ in South Africa - OSIRIS in France was shut down at the end of 2015), which frequently have to be shut down for maintenance, risking a global shortage of molybdenum-99.

The risks associated with the production of radioisotopes in research reactors obviously include the risks of contamination and irradiation of operational personnel and the risk of radioactive releases into the environment.

\subsubsection{Cancer treatment by neutron capture}

A number of research reactors are used to treat cancer (melanomas, brain tumours). The method they use, which is referred to by the acronym BNCT (Boron Neutron Capture Therapy), is based on the absorption of neutrons by boron-10. It consists of injecting a boron-10 solution into the tumour to be treated and irradiating it with a neutron beam from the reactor. The absorption of neutrons by the boron-10 leads to the emission of $\alpha$ (alpha) particles, which are highly ionizing. The cancer cells are destroyed locally by these particles, the distance of travel of which is of the same order of magnitude as the diameter of the cells.

Further research is necessary to reduce the irradiation time of the patients and the doses received by healthy cells.

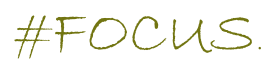

\section{Artificial radionuclides produced at research reactors and used in the medical sector}

- Diagnostic techniques:

Technetium-99m (from molybdenum-99), xenon-133, tritium $\left({ }^{3} \mathrm{H}\right)$, carbon-14, ruthenium-97, iodine-125;

- Therapeutic treatments:

- $\quad \boldsymbol{\beta}$ emitters (for synovitis, stenosis (diseases of the arteries), palliative treatments (bone cancer): yttrium-90, strontium-90, rhenium-186, erbium-169, copper-64, samarium-153,

- $\gamma$ emitters (for cancers): cobalt-60, iridium-192,

- $\quad \boldsymbol{\beta}$ and $\gamma$ emitter (for thyroid cancer and hyperthyroidism): iodine-131.

\subsubsection{Activation analysis}

Activation analysis is a method for precisely determining traces of impurities in samples of materials required to have a high chemical purity. It is based on the conver-

36. South African Fundamental Atomic Research Installation 1. 
sion of stable atomic nuclei into radioactive nuclei through neutron irradiation of the sample being tested and on measurement of the radiation emitted by the radionuclides formed in the irradiated material.

Activation analysis is the most common area of use of research reactors. Practically any reactor with a power of more than around 20 kilowatts can provide a sufficient neutron flux to perform these analyses. By using hydraulic or pneumatic tubes linking the reactor to the analysis laboratories, elements with a short radioactive half-life can be measured.

From a safety point of view, the risks associated with this type of research reactor use are generally low. They are the risk of contamination of premises or persons in the analysis laboratories, the risk of irradiation if a container carrying an irradiation capsule in a hydraulic or pneumatic tube system becomes trapped, and the risk of contamination of internal structures within the reactor if the irradiated samples overheat, causing the loss of integrity of these structures and the destruction of the irradiation capsule. The measures to be taken to avoid the above situations and to limit their consequences, and the list of materials which must not be irradiated in a reactor (e.g. mercury because of its corrosive properties), must be stated in the facility's operating rules.

\subsubsection{Industrial applications}

There are numerous industrial applications for research reactors. Only three of them, which are very common, will be mentioned below.

Neutron beams can be used for neutron radiography of various objects. Nondestructive testing using neutron radiography, which is based on the property of neutrons that they are stopped by light nuclei, is a complementary technique to radiography, because it enables both thin slivers of light elements and thick pieces of heavy elements to be examined. Neutron radiography is used for non-destructive testing in the aeronautical and space industries (e.g. for testing the pyrotechnic devices in rocket launchers), and in the nuclear sector. An example is the facility used for the neutron radiography of irradiated fuels associated with the PHENIX reactor at Marcoule, France, which consists mainly of a small reactor with a vessel containing a fissile solution (uranyl nitrate), equipped with a cooling system, a fixed reflector and a mobile reflector, which can be moved closer to the vessel to start the chain reaction.

The neutron irradiation of silicon ingots changes the silicon through the uniform generation of phosphorus-31, which turns it into a semi-conductor. This method can be used to achieve an excellent distribution of resistivity in silicon ingots used in the manufacture of components for the electronics industry, such as diodes and thyristors.

Irradiation with fast neutrons causes colouration of topaz, which is used in jewellery-making. This activity is prohibited in many countries, but is still carried out in some research reactors throughout the world. 